\title{
Comparison of Matrix-Assisted Laser Desorption Ionization Time of Flight Mass Spectrometry with VITEK2 Gram positive system for identification of beta hemolytic Streptococci
}

\author{
Yesim Besli $^{1 *}$, Meltem Ayas ${ }^{2}$, Onur Karatuna ${ }^{3}$, Isın Akyar ${ }^{1}$ \\ ${ }^{1}$ Acibadem University School of Medicine Medical Microbiology Department, Acibadem Labmed Clinical Laboratories, \\ Istanbul, Turkey. ${ }^{2}$ Acibadem Labmed Clinical Laboratories, Istanbul, Turkey. ${ }^{3}$ Acibadem University School of \\ Medicine, Medical Microbiology Department, Istanbul, Turkey.
}

\begin{abstract}
Background: Matrix-assisted laser desorption ionization time-of-flight mass spectrometry (MALDI-TOF MS) is known as a successful tool for bacterial identification and suitable for clinical diagnostics. The aim of our study was to evaluate diagnostic accuracy of MALDI-TOF MS system and VITEK2 Gram Positive Identification (GP ID) system for the identification of Beta Hemolytic Streptococci (BHS).

Materials and Methods: A total 148 BHS which were isolated from various clinical specimens were included in the study. Isolates were identified by Bruker Biotyper 3.4 and VITEK2 GP ID coupled to the agglutination test. Identification results for Bruker Biotyper 3.4 and VITEK2 GP ID systems were classified in three different categories as follows: correct identification, low level of discrimination, no identification/misidentification. Identification results of BHS were evaluated according to these categories.

Results: BHS isolates were defined as Streptococcus pyogenes (n: 69), Streptococcus agalactiae (n: 59), Streptococcus dysgalactiae serogroup C (n: 5), and Streptococcus dysgalactiae serogroup G (n: 15) according to latex agglutination assay. MALDI-TOF MS analysis of 148 BHS isolates yielded correct identification for $89.9 \%$ of $S$. pyogenes, $64.4 \%$ of $S$. agalactiae, and $95.0 \%$ S. dysagalactiae serogroup C and G; while VITEK2 GP ID gave correct identification for $62.3 \%$ of $S$. pyogenes, $67.8 \%$ of $S$. agalactiae, and $65.0 \%$ of $S$. dysagalactiae serogroup C and G.

Conclusions: MALDI-TOF MS-based identification provides faster and more accurate identification of beta-hemolytic streptococcal species than VITEK2 GP ID system.
\end{abstract}

Key words: MALDI-TOF, VITEK, Beta Hemolytic Streptococci, S. pyogenes, S. agalactiae, S. dysagalactiae

**This study was presented as a poster at the XXXVII. Turkish Microbiology Congress, $16-20^{\text {th }}$

November 2016, Antalya, Turkey.

*Corresponding Author: Yeşim Beşli, Acıbadem Labmed Clinical Laboratories, Microbiology Department, Istanbul, Turkey. Phone: +90 216500 4745;

E-mail: yesim.besli@acibademlabmed.com.tr Received: Nov 23, 2017. Accepted: Dec 23, 2017.
This is an Open Access article distributed under the terms of the Creative Commons Attribution Non-Commercial License (http://creativecommons.org/licenses/bync/4.0/) which permits unrestricted non-commercial use, distribution, and reproduction in any medium, provided the original work is properly cited. 


\section{Introduction}

Streptococcus pyogenes and Streptococcus agalactiae are two species of betahemolytic streptococci (BHS) are simply identified by conventional methods and serogrouping (1-3). As for the rest, there are some challenges. Because Streptococcus dysgalactiae can contain both Lancefield groups C and G, and rarely A. Different species have been shown to contain Lancefield groups $\mathrm{C}$ and $\mathrm{G}$, also $(1,4)$.

However Matrix-Assisted Laser Desorption Ionization-Time of Flight Mass Spectrometry (MALDI-TOF MS) is presented as a reliable tool to use in clinical laboratories, results for beta-hemolytic streptococci have been conflicting (5-7). The VITEK2 Gram Positive Identification (GP ID) system is a more commonly used bacterial identification tool in medical laboratories. In this system identification is primarily based on biochemical tests measuring carbon source utilization, inhibition and resistance, and enzymatic activities, and identification of BHS by VITEK2 requires supplemental tests $(8,9)$.

In order to evaluate diagnostic accuracy of two different systems, we compared identification results of MALDI-TOF MS system with VITEK2 GP ID system.

\section{Material and methods}

\section{Bacterial isolates and conventional identification}

A total of 148 BHS strains which isolated from throat (n: 74), urine (n: 43), female genital tract specimens (n: 20), skin and soft tissue samples (n: 6), lower respiratory tract specimens (n: 3), and blood (n: 2) sent to the Central Microbiology Department of Acibadem Labmed Clinical Laboratories, were included in the study. Colonies with pinpoint to medium size, and translucent hemolysis zone (beta-hemolysis) on $5 \%$ sheep blood agar plates were defined as BHS. Conventional methods such as gram stain, bacitracin and trimethoprim/sulfamethoxazole susceptibility test, PYR (pyrrolidonylarylamidase activity) test, and CAMP (Christie, Atkins, and MunchPeterson) test were used in identification (1-3). Strains were stored in brain heart infusion broth with glycerol at $-80^{\circ} \mathrm{C}$, and were subcultured on $5 \%$ sheep blood agar plates, and incubated $5 \% \mathrm{CO} 2$ at $35^{\circ} \mathrm{C}$ for $18-24 \mathrm{~h}$. Lancefield grouping of those strains were achieved by the latex agglutination kit. Identification of the strains was also performed simultaneously by MALDI TOF MS (microflex LT, Bruker, Bremen, Germany) and VITEK 2 systems (bioMérieux, USA).

\section{Latex agglutination assay}

Lancefield Serogroups of isolates were determined by STREP Test Kit (Plasmatec, UK) which containing the Streptococcus group specific antiserum. According to the manufacturer's instructions; the purely isolated 2-5 BHS colonies were suspended in $300 \mu \mathrm{L}$ of extraction enzyme and incubated for $15 \mathrm{~min}$ at $37^{\circ} \mathrm{C}$. Then $50 \mu \mathrm{L}$ of this suspension was dropped on one drop of the reagent containing latex beads coated with the antibody against each group polysaccharide antigen which had previously dropped onto the test cards. Rotational movements were performed by orbital shaker (OS-20, Orbital Shaker, Biosan Ltd., Latvia) to determine visible agglutination of the latex particles. 


\section{MALDI-TOF}

Bruker Daltonics Microflex LT system was used and measurements were performed according to manufacturer's recommended settings. Obtained spectra were analyzed using Maldi Biotyper Automation Control and Bruker Biotyper software version 3.4 (Bruker Daltonics, Bremen, Germany). MALDI TOF target plates were inoculated by applying a small amount of a single freshly grown overnight colony directly onto a ground steel MALDI TOF target plate in a thin film. The microbial film was then overlaid with $1.5 \mu \mathrm{L}$ of a MALDI matrix (a saturated solution of -cyano-4hydroxycinnamic acid in 50\% acetonitrile-2.5\% trifluoroacetic acid) and allowed to dry at room temperature. The plate was inserted into the source of a MicroFlex MALDI-TOF MS instrument (Bruker Daltonics, Bremen, Germany). Mass spectra were collected from 2,000 to 20,000 Da in linear ion mode, using 240 shots of a 20$\mathrm{Hz}$ nitrogen laser for ionization.

\section{Vitek 2 identification}

According to the manufacturer's instructions; the inoculum suspension was prepared from the overnight, pure cultures that were grown on 5\% sheep blood agar (bioMérieux). Bacterial suspensions were prepared extemporaneously by suspending bacterial isolates in $0.45 \%$ saline to the equivalent of a $0.5-0.63$ McFarland turbidity standard with the VITEK-2 Densichek instrument. The ID-GP identification cards, that is a 64-well plastic card that includes 43 tests, were inserted the each tubes and data were analyzed using VITEK-2 database, version 06.00.014.

\section{Interpretation Criteria}

Identification results were classified in three different categories. For MALDI-TOF identification criteria used in our analysis were as follows: (i) correct identification (correct identification, with a score of $2.00-3.00$, at the species level); (ii) low level of discrimination (correct identification, with a score of 1.70 to 1.99 , at the genus level), (iii) no identification/misidentification (identification with a score of $<1.70$, or no identification). As for VITEK2 system, (i) correct identification is defined as identification to the species level as the only choice with a $\geq 93 \%$ probability; (ii) low level of discrimination (either identification to the genus level or a low level of discrimination between two or more species, including the correct species); (iii) no identification/misidentification (the species identified with the GP identification card was different from that identified by conventional identification and latex agglutination or organism was unidentified) (10-12).

\section{Results}

A total of 148 isolates of BHS were classified as group A (n: 69), group B (n: 59), group C (n: 5), group $\mathrm{G}(\mathrm{n}: 15)$ by the latex agglutination method.

MALDI-TOF MS yielded correct identification to the species level in $89.9 \%$ (n: 62) of S. pyogenes, $64.4 \%$ (n: 38) of S. agalactiae, $95.0 \%$ (n: 19) of S.dysagalactiae, and low level of discrimination in $10.1 \%$ (n: 7) of S. pyogenes, $35.6 \%$ (n: 21) of S. agalactiae isolates. Overall MALDI-TOF MS provided identification to the species level in $80.4 \%$ (n: 119) of BHS and low level of discrimination in $18.9 \%$ (n: 28) of BHS while it failed to identify $0.7 \%$ (n: 1) of BHS. 
VITEK2 GP system could correctly identify $62.3 \%$ (n: 43) of S. pyogenes, $67.8 \%$ (n: 40) of $S$. agalactiae, $65.0 \%$ (n: 13) of $S$. dysagalactiae isolates to the species level in. It provided low level of discrimination in $26.1 \%$ (n: 18) of $S$.pyogenes, $25.4 \%$ (n: 15) of S. agalactiae, $5.0 \%$ (n: 1) of S. dysagalactiae isolates. Identification to the species level in 64.9\% (n: 96) of BHS and low level of discrimination in $22.9 \%$ (n: 34) of BHS was achieved by VITEK 2 GP, however $12.2 \%$ (n: 18) of BHS isolates were not identified or misidentified by this system (Table 1 ).

Table 1. Comparison of identification results of MALDI-TOF Mass Spectrometry with VITEK2 GP Identification for Beta hemolytic Streptococci.

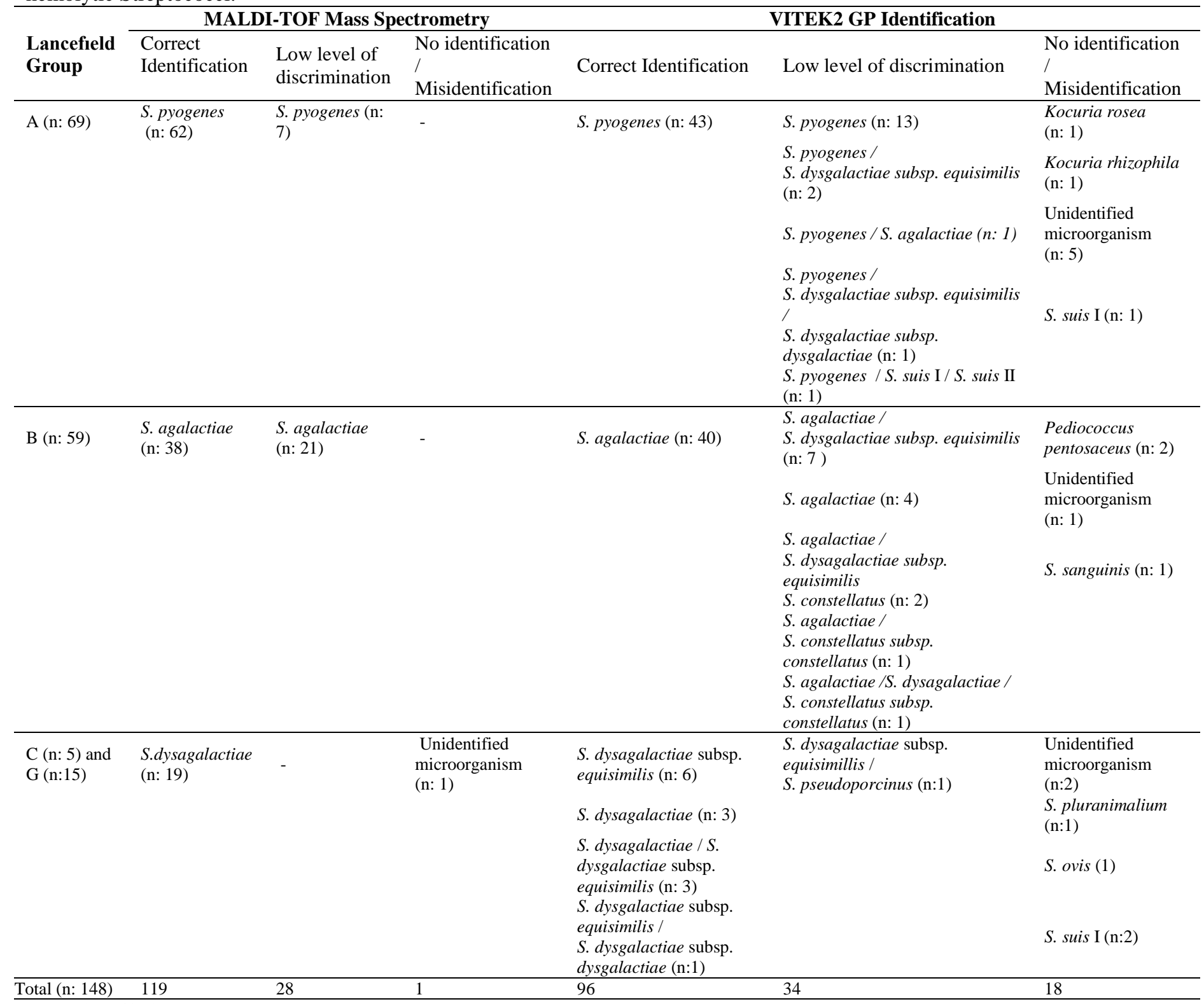




\section{Discussion}

MALDI-TOF is concerned as a reliable and cost-effective method for bacteria identification in the microbiology laboratory, even so there are conflicts in identification results of BHS by this method $(7,11,13-16)$. On the other hand VITEK 2 GP system is one of the respectable systems by providing reliable results for the identification of GP cocci under clinical microbiology laboratory conditions $(8,12)$. In the present study, identification by MALDI-TOF was achieved $99.3 \%$ of BHS in general, although low level of discrimination was observed at $10.1 \%$ of $S$. pyogenes and $35.6 \%$ of $S$. agalactia. VITEK2 GP identified $87.8 \%$ of all BHS but it gave lower than $93 \%$ probability rates for $26.1 \%$ of S. pyogenes, $25.4 \%$ of S. agalactiae. $95.0 \%$ of BHS which were classified Group C or G, were identified as $S$. dysagalactiae by MALDI-TOF. On the other hand, $65.0 \%$ of these isolates were identified as different subspecies of $S$. dysagalactiae by VITEK 2 GP system. Similarly, Cherkaoui et al. also compared MALDI-TOF MS with VITEK 2 GP system for the identification of 386 BHS. All of the isolates were identified with high confidence scores using MALDI-TOF, while only $85 \%$ of them were identified with high confidence using VITEK2 GP system (14). But identification results for BHS by MALDI-TOF varies based on low number of analyzed strains, preparation methods, differences in the amount of bacteria applied to the MALDI-TOF target, and the identification criteria used in interpreting MALDI-TOF results $(2,7,11,13-17)$. In the studies that are included higher number of BHS correct identification rates are 94-100\% in S.pyogenes, $75-100 \%$ in S.agalactiae, and $93-100 \%$ in S. dysagalactiae isolates for MALDI-TOF identification $(13,14,17)$. Also correct identification of bacteria using MALDI-TOF depends on the reference spectra present in the database, and the database of MALDI-TOFF system is regularly updated with spectra from species (7). Database analyzed spectra of the BHS in the present study is newer than the studies mentioned before $(7,9,13-17)$. However the database we used does not include a major change for BHS, our correct identification rates were considerably high by using MALDI-TOFF. Besides, the VITEK 2 GP identification system is redesigned to achieve greater accuracy in the identification of Gram-positive cocci in routine laboratory (12). In this study, $87.8 \%$ of the BHS isolates were correctly identified by using VITEK2 GP identification system without application of any further additional tests.

Even both of MALDI-TOF and VITEK2 GP systems were identified all Lancefield group C (n: 5) and G (n: 15) isolates as $S$. dysagalactiae, we could not verify these isolates are $S$. dysagalactia. Since it is hard to differentiate species belonging to the Lancefield groups $\mathrm{C}$ and $\mathrm{G}$ streptococci phenotypically, it requires either molecular methods or standardized phenotypic identification systems $(18,19)$.

\section{Conclusion}

Our results have emphasized that MALDI-TOF MS is powerful tool for the identification of BHS. Considering that MALDI-TOF MS is cost effective in long term use, user friendly. It is appropriate in routine clinical microbiology laboratories in identifying BHS, as well most of clinically important bacteria. 
Ethics Committee Approval: NA

Informed Consent: NA

Peer-review: Externally peer-reviewed.

Conflict of Interest: No conflict of interest was declared by the author.

Financial Disclosure: The author declared that this study has received no financial support.

\section{References}

1. Facklam R. What happened to the streptococci: overview of taxonomic and nomenclature changes. Clin Microbiol Rev. 2002;15 (4): 13-30.

2. Spellerberg B, Brandt C. Streptococci. In: Murray PR, Baron EJ, Jorgensen J, Pfaller M, Landry Ml, editors. Manual of clinical microbiology, 9th edn. Washington, D.C: ASM press; 2007 pp 412-30.

3. Whiley R, Hardie JM. The streptococci. In: Vos P, Garrity G, Jones D, Krieg NR, Ludwig W, Rainey FA, Schleifer KH, Whitman W, editors. Bergeys manual of systematic bacteriology. New York: Springer; 2009 pp 689-90.

4. Brandt C, Haase G. Characterization of blood culture isolates of Streptococcus dysgalactiae subsp. equisimilis possessing lancefield's group aantigen. J Clin Microbiol. 1999; 37(12): 4194-7.

5. Nomura F. Proteome-based bacterial identification using matrix-assisted laser desorption ionization-time of flight mass spectrometry (MALDI-TOF MS): A revolutionary shift in clinical diagnostic microbiology. Biochim Biophys Acta. 2015; 1854(6): 528-537.

6. Fan WT, Qin TT, Bi RR, Kang HQ, Ma P, Gu B. Performance of the matrix-assisted laser desorption ionization time-of-flight mass spectrometry system for rapid identification of streptococci: a review. Eur J Clin Microbiol Infect Dis 2017; 36(6):1005-1012.

7. Jensen CS, Dam-Nielsen C, Arpi M. Matrix-assisted laser desorption/ionization-time of flight mass spectrometry identification of large colony beta-hemolytic streptococci containing Lancefield groups A, C, and G. Infect Dis (Lond) 2015; 47(8): 575-579.

8. Crowley E, Bird P, Fisher K, Goetz K., Boyle M, et al. Evaluation of the VITEK 2 gram positive (GP) microbial identification test card: collaborative study. Journal of AOAC International. 2012; 95(5): 1425-1432.

9. Vitek 2 Systems, GP Product Information, 069042-6EN1, 4:1-24.

10. i Y, Gu B, Liu G, Xia W, Fan K, Mei Y, et al. MALDI-TOF MS versus VITEK 2 ANC card for identification of anaerobic bacteria. J Thorac Dis. 2014; 6(5): 517-23.

11. Bizzini A, Durussel C, Bille J, Greub G, Prod'hom G. Performance of matrix-assisted laser desorption ionization-time of flight mass spectrometry for identification of bacterial strains routinely isolated in a clinical microbiology laboratory. J Clin Microbiol. 2010;48(5): 154954.

12. Funke G, Funke-Kissling P. Performance of the new VITEK 2 GP card for identification of medically relevant gram-positive cocci in a routine clinical laboratory. J Clin Microbiol. 2005; 43(1): 84-88.

13. Neville SA, Lecordier A, Ziochos H, Chater MJ, Gosbell IB, et al. Utility of matrix-assisted laser desorption ionization-time of flight mass spectrometry following introduction for routine laboratory bacterial identification. J Clin Microbiol. 2011; 49(8): 2980-4.

14. Cherkaoui A, Emonet S, Fernandez J, Schorderet D, Schrenzel J. Evaluation of matrixassisted laser desorption ionization-time of flight mass spectrometry for rapid identification of beta-hemolytic streptococci. J Clin Microbiol 2011; 49(8): 3004-5.

15. Van Veen SQ, Claas ECJ, Kuijper EJ. High-throughput identification of bacteria and yeast by matrix-assisted laser desorption ionization-time of flight mass spectrometry in conventional medical microbiology laboratories. J Clin Microbiol 2010; 48(3): 900-7. 
16. Alatoom AA, Cunningham SA, Ihde SM, Mandrekar J, Patel R. Comparison of direct colony method versus extraction method for identification of gram-positive cocci by use of Bruker Biotyper matrix-assisted laser desorption ionization-time of flight mass spectrometry. J Clin Microbiol. 2011; 49(8): 2868-73.

17. Zhou C, Tao L, Hu B, Ma J, Ye X, Huang S, et al. Matrix-assisted laser desorption/ionization time-of-flight mass spectrometry for the identification of beta-hemolytic streptococc.i J Thorac Dis. 2015; 7(4):591.

18. Lamm CG, Ferguson AC, Lehenbauer TW, Love BC. Streptococcal infection in dogs: a retrospective study of 393 cases. Vet pathol 2010; 47(3): 387-95.

19. Whatmore AM, Engler KH, Gudmundsdottir G, Efstratiou A. Identification of isolates of Streptococcus canis infecting humans. J Clin Microbiol 2001; 39(11): 4196.

\section{Submit your next manuscript to the JICM and take full advantage of:}

Convenient online submission,

Thorough peer review, Fast Response,

No charges,

Immediate publication on acceptance,

Inclusion in Scopemed and High quality indexes,

Research which is freely available for redistribution of the worldwide literature

To submit your manuscript, click on $h t t p: / / w w w . j i a c m . c o m$

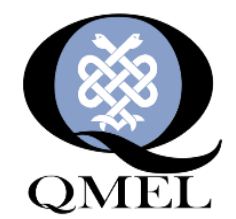

Medicine \& Publishing

Published by The QMEL ${ }^{\circledR}$.org

Medicine \& Education \& Library

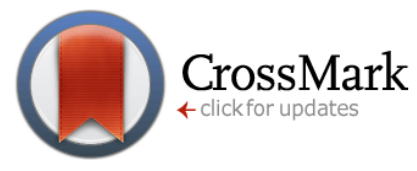

